\title{
miR-302c-3p and miR-520a-3p suppress the proliferation of cervical carcinoma cells by targeting CXCL8
}

\author{
HONG-MEI DING $^{1 *}$, HONG ZHANG $^{1 *}$, JUAN WANG $^{1}$, JIN-HUA ZHOU $^{1}$, FANG-RONG SHEN $^{1}$, \\ RU-NING JI ${ }^{2}$, JIA-YIN SHI ${ }^{3}$ and YOU-GUO CHEN ${ }^{1}$ \\ ${ }^{1}$ Department of Obstetrics and Gynaecology, The First Affiliated Hospital of Soochow University, Suzhou, Jiangsu 215006; \\ Departments of ${ }^{2}$ Medical Engineering and ${ }^{3}$ Dermatology, Suzhou Municipal Hospital, Suzhou, Jiangsu 215008, P.R. China
}

Received December 4, 2019; Accepted November 9, 2020

DOI: $10.3892 / \mathrm{mmr} .2021 .11961$

\begin{abstract}
The aim of the present study was to identify the differentially expressed microRNAs (miRs) in cervical carcinoma (CC) tissues and cells and to explore the function of miR-302c-3p and miR-520a-3p in the proliferation of CC cells. Potential dysregulated miRNAs in CC tissues and tumour-adjacent tissues were detected. Reverse transcription-quantitative PCR (RT-qPCR) was performed to determine the expression of miR-302c-3p, miR-520a-3p and CXCL8 in CC tissues and cell lines. The target genes of the miRNAs were predicted using miRTarBase and verified by luciferase reporter assays. RT-qPCR and western blotting were performed to measure the expression of C-X-C motif ligand (CXCL) 8 after transfection. The effect on proliferation was verified by Cell Counting Kit assay and ethynyl-2-deoxyuridine staining. Flow cytometry was utilised to assess the effect on apoptosis. In the present study, miR-302c-3p and miR-520a-3p were markedly downregulated in $\mathrm{CC}$ cell lines compared to the normal cervical cell line H8. Functionally, overexpression of miR-302c-3p and/or miR-520a-3p inhibited proliferation and promoted the apoptosis of $\mathrm{CC}$ cell lines in vitro, while the knockdown of miR-302c-3p and/or miR-520a-3p had the opposite effect. Furthermore, miR-302c-3p and miR-520a-3p could both bind to CXCL8. Inhibition of CXCL8 in combination with miR-302c-3p and/or miR-520a-3p overexpression exerted proliferation-suppressive and apoptosis-stimulating effects on CC cells, whereas restoring CXCL8 attenuated the miR-302c-3p- and miR-520a-3p-induced anti-proliferative and pro-apoptotic effects. miR-302c-3p and miR-520a-3p suppress the proliferation of $\mathrm{CC}$ cells by downregulating the expression
\end{abstract}

Correspondence to: Dr You-Guo Chen, Department of Obstetrics and Gynaecology, The First Affiliated Hospital of Soochow University, 188 Shizi Street, Gusu, Suzhou, Jiangsu 215006, P.R. China

E-mail: ygchen64@163.com

*Contributed equally

Key words: cervical carcinoma, miR-302c-3p, miR-520a-3p, $\mathrm{C}-\mathrm{X}-\mathrm{C}$ motif ligand 8, proliferation, apoptosis of CXCL8, which may provide a novel target for the treatment of $\mathrm{CC}$.

\section{Introduction}

Cervical carcinoma (CC) is one of the leading causes of cancer-related death in females (1), with an increasing incidence in relatively young females (2). It is of great importance to investigate the mechanisms of tumourigenesis and development of CC to facilitate its therapy.

As a type of small non-coding RNA, microRNAs (miRNAs) can post-transcriptionally modify target gene expression by binding to 3'-untranslated regions (3'-UTRs), followed by translational inhibition or degradation of mRNAs (3). miRNAs can either be cancer-promoting, by inhibiting anti-oncogenes, or cancer-suppressing, by inhibiting oncogenes (3). Accumulating evidence has proven that miRNAs can impact tumour metastasis in a broad spectrum of human malignancies. For instance, excessive maturation of miR-25-3p via m6A modification, which can be induced by cigarette smoking, promotes the development of pancreatic cancer (4), and miR-375 has been described as a crucial regulator of phagocyte infiltration (5). Moreover, miRNAs have been reported to modulate tumour proliferation by regulating target genes. MiRNA-145, for instance, was reported to inhibit the proliferation of non-small cell lung cancer cells by targeting c-Myc (6). However, the roles of miRNAs, especially proliferation-relevant miRNAs, in CC remain to be clarified.

miR-302c-3p and miR-520a-3p are known as tumour suppressors in several types of cancer, including glioma (7), renal cell carcinoma (8), and hepatocellular carcinoma (9). However, the biological functions of miR-302c-3p and miR-520a-3p in CC, particularly in CC proliferation, are still unclear. Moreover, given that miR-302 and miR-520 can regulate the natural killer group $2 \mathrm{D}$ ligands major histocompatibility complex class I chain-related proteins A and B and unique long 16-binding protein 2 to counter the resistance of Kasumi-1 cells to natural killer cells (10), it remains unclear whether miR-302c-3p and miR-520a-3p can act co-operatively to regulate $\mathrm{CC}$ metastasis and proliferation.

C-X-C motif ligand (CXCL)8 (CXCL8), also known as interleukin-8 (IL-8), is a pro-inflammatory CXC chemokine that is associated with the promotion of neutrophil chemotaxis 
and degranulation (11). Under normal circumstances, the expression of CXCL8 in tissues is low or undetectable; however, increased expression of CXCL8 is detected in some human solid tumours, such as cervical cancer (12), ovarian cancer $(13,14)$, and non-small cell lung cancer (15). CXCL8 produced by cancer cells in response to epithelial-mesenchymal transition (EMT) is involved in various biological cell phenotypes, such as cell proliferation, migration and metastasis (16). More importantly, in microsatellite-unstable colorectal cancer, CXCL8 production and cell proliferation is enhanced by the loss of miR-484 (17), indicative of a regulatory role for CXCL8 and miRNAs. Although CXCL8 is not a novel target in CC, as it has previously been reported to be upregulated in CC (18), the present study focused on investigating the relationship between miR-302c-3p, miR-520a-3p and CXCL8.

In the present study, differentially expressed miRNAs between $\mathrm{CC}$ tissues and adjacent normal tissues were screened by literature review and based on the author's unpublished data (data not shown). Of the 25 selected miRNAs, the effect of miR-302c-3p and miR-520a-3p on CC cell proliferation was investigated. The aim of the present study was to explore the cooperative effects of miR-302c-3p and miR-520a-3p on CC cells to gain a deeper understanding of $\mathrm{CC}$ proliferation and provide a potential target for the treatment of $\mathrm{CC}$.

\section{Materials and methods}

Patient samples. In total, 20 patients with recently diagnosed (and previously untreated) CC at the Department of Obstetrics and Gynaecology of The First Affiliated Hospital of Soochow University from July 2016 to August 2017 were selected in a single-centre study and had a median age of 51 years (range, 39-75). The CC tissues and tumour-adjacent tissues were collected from the selected patients following diagnostic evaluation. Written informed consent was obtained from each patient prior to the experiment. The protocols were also approved by the local ethics committee of The First Affiliated Hospital of Soochow University. All the clinical samples collected in the present study are squamous cell carcinoma.

Cell culture. Human CC cell lines (HeLa-S3 and C-33A), immortalized cervical epithelial cell line (H8) and human embryonic kidney cells (293T) were obtained from the Cell Resource Center of the Chinese Academy of Sciences (Shanghai, China). Cells were cultured in DMEM (HyClone, Cytiva) containing 10\% foetal bovine serum (Gibco, Thermo Fisher Scientific) and $100 \mathrm{U} / \mathrm{ml}$ penicillin/streptomycin (HyClone, Cytiva) in a $37^{\circ} \mathrm{C}$ constant incubator with $95 \%$ air and $5 \% \mathrm{CO}_{2}$.

$R N A$ extraction and reverse transcription-quantitative PCR (RT-qPCR). Total RNA of tissues and cell lines was extracted using the RNeasy Plus Universal Tissue kit (Sangon Biotech Co.) based on the manufacturer's instructions. miRNAs from CC cell lines were extracted using the miRNeasy Mini Kit (Sangon Biotech Co). PCR primers for 25 potentially dysregulated miRNAs and U6 were synthesized by Guangzhou RiboBio.

Primers for CXCL8 and GAPDH were synthesized by Takara (Sangon Biotech Co.) (Table I). cDNA was constructed using the PrimeScript RT reagent kit (Takara Biotechnology Co., Ltd.). Real-time PCR was performed using SYBR premix Ex Taq II (Takara Biotechnology Co., Ltd.), and fluorescence intensity was detected in a Light Cycler 480 system (Roche Applied Science) using the following thermocycling conditions: $95^{\circ} \mathrm{C}$ for $10 \mathrm{~min}, 40$ cycles of $95^{\circ} \mathrm{C}$ for $15 \mathrm{sec}$ and $60^{\circ} \mathrm{C}$ for $1 \mathrm{~min}$. GAPDH was used as the internal control. The comparative $\mathrm{Cq}\left({ }^{\Delta \Delta \mathrm{Cq}}\right)$ method (19) was used to calculate the fold change for each miRNA/mRNA. U6 and GAPDH were treated as internal controls. The following formulas were used to calculate the expression fold changes $(X): \Delta \mathrm{Cq}=\mathrm{Cq}$ (target miRNA/mRNA)-Cq (U6/GAPDH), $\Delta \Delta \mathrm{Cq}=\Delta \mathrm{Cq}$ (target miRNAs/mRNA)- $\Delta$ Cq (target miRNAs/mRNA), $X=2^{-\Delta \Delta C q}$.

miRNAs, siRNAs and plasmids. Human miR-302c-3p and miR-520a-3p mimics as well as scrambled miR-302c-3p mimics, miR-520a-3p mimics and small interfering RNAs were obtained from Guangzhou RiboBio. A CXCL8 eukaryotic expression vector (CXCL8/pcDNA3.1) was generated by inserting the open reading frame of CXCL8 into pcDNA3.1, using the empty vector as a negative control. For luciferase reporters, the 3'-UTR of CXCL8 was amplified from human genomic DNA before the miR-302c-3p and miR-520a-3p binding sites within the CXCL8 3'-UTR were mutated to remove complementarity. The mutant or wild-type 3'-UTR of CXCL8 were cloned into the psiCHECK-2 luciferase vector (cat. no. 78260; Promega Corporation). All plasmids were confirmed by sequencing.

Cell proliferation assay. Cell counting kit (CCK-8, Merck $\mathrm{KGaA}$ ) and ethynyl-2-deoxyuridine (EdU, Guangzhou RiboBio) staining were both utilised to measure the proliferation ability of each cell line under different conditions. For the CCK- 8 assay, $5 \times 10^{3}$ cells in $100 \mu 1$ were transferred to each well of a 96 -well plate. Cells were cultured at $37^{\circ} \mathrm{C}$ before CCK-8 solution $(10 \mu \mathrm{l})$ was added to each well $24,48,72$, and $96 \mathrm{~h}$ later. Subsequently, the cells were incubated at $37^{\circ} \mathrm{C}$ for an additional $4 \mathrm{~h}$ before OD values $(450 \mathrm{~nm})$ were measured using a microplate reader (Bio-Rad Laboratories, Inc.). For the EdU assay, the cells were transfected with miR-302 and miR-520 mimic or inhibitor $(100 \mathrm{nM})$ using Lipofectamine ${ }^{\circledR} 2000$ (Invitrogen; Thermo Fisher Scientific, Inc.) and incubated with $100 \mu \mathrm{l}$ of $50 \mu \mathrm{M}$ EdU per well for $2 \mathrm{~h}$ at $37^{\circ} \mathrm{C}$. Cells were visualized by fluorescence microscopy and the ratio of EdU/DAPI was calculated to analyse the EdU assay. Experiments were repeated at least three times.

Flow cytometry assay. Cell apoptosis was assessed with the Annexin V-FITC apoptosis detection kit (Elabscience). Flow cytometry was performed with FACSCalibur (BD Biosciences) and all experiments were performed at least three times.

Luciferase assay. The potential direct target genes of miR-302c-3p and miR-520a-3p were predicted by miRTarBase (mirtarbase.mbc.nctu.edu.tw/php/index.php). For the luciferase reporter assays, 293T cells were seeded onto 24-well plates before miR-302c-3p or miR-520a-3p mimics $(100 \mathrm{nM})$ and wild-type or mut-type CXCL8 3'-UTR $(1.5 \mu \mathrm{g})$ were co-transfected into $293 \mathrm{~T}$ cells using Lipofectamine 2000 (Invitrogen; Thermo Fisher Scientific, Inc.). After 
Table I. Primers for RT-qPCR.

\begin{tabular}{lll}
\hline Gene name & & \\
\hline miR-302c-3p & Primer sequence $\left(5^{\prime} \rightarrow 3^{\prime}\right)$ \\
& $\begin{array}{l}\text { Forward } \\
\text { Reverse }\end{array}$ & CAGTCGTATCCAGTGCAGGGTCCGAGGTATTCGCACTGGATACGACCCACTG \\
miR-520a-3p & RT primer & CTCAACTGGTGTCGTGGAGTCGGCAATTCAGTTGAGACAGTCCAAA \\
& Forward & ACACTCCAGCTGGGAAAGTGCTTCCC \\
CXCL8 & Reverse & CTCAACTGGTGTCGTGGA \\
& Forward & CAGAGCAACGTGCTCCAAAGTC \\
U6 & Reverse & GAAGCGTTGCTGTCGGTTCA \\
& Forward & CTCGCTTCGGCAGCACA \\
GAPDH & Reverse & AACGCTTCACGAATTTGCGT \\
& Forward & CTGGGCTACACTGAGCACC \\
& Reverse & AAGTGGTCGTTGAGGGCAATG
\end{tabular}

RT-qPCR, reverse transcription-quantitative PCR; miR, microRNA; CXCL8, C-X-C motif ligand 8.

transfection for $48 \mathrm{~h}$, cells were collected and lysed for luciferase assays. The intensity of luciferase activity was measured using the Dual-Luciferase Reporter Assay System (Promega Corporation). Renilla luciferase was used for normalization. Each experiment was performed at least three times.

Western blot analysis. Whole-cell lysates were prepared using RIPA buffer (Beyotime Institute of Biotechnology). Extracts were mixed with SDS-PAGE loading buffer and denatured by boiling for $5 \mathrm{~min}$. Equal amounts of protein $(\sim 30 \mu \mathrm{g})$ were separated on $10 \%$ SDS-PAGE gels and transferred onto polyvinylidene fluoride (PVDF) membranes (Bio-Rad Laboratories, Inc.). Blots were blocked using 5\% bovine serum albumin (BSA, Gibco; Thermo Fisher Scientific, Inc.) for $2 \mathrm{~h}$ and incubated overnight at $4^{\circ} \mathrm{C}$ with primary antibodies against CXCL8 (1:1,000; cat. no. ab154390; Abcam) and $\beta$-actin (1:5,000; cat. no. 4970S; Cell Signaling Technology, Inc.). PVDF membranes were washed with Tris-buffered saline (TBS) supplemented with $0.05 \%$ Tween-20 before incubation with HRP-conjugated secondary antibody $(1: 2,000$; cat. no. 7074S; Cell Signaling Technology, Inc.) for $2 \mathrm{~h}$ at room temperature. Signals were visualized using enhanced chemiluminescence reagents (Thermo Fisher Scientific, Inc.). Densitometric analysis of the blot bands was performed using ImageJ 1.48 software, and the intensity values were normalized against the values of the $\beta$-actin loading control. All experiments were performed at least three times.

Statistical analysis. Data were analysed using SPSS software (version 19; IBM Corp.). Continuous data sets are expressed as the mean \pm SEM. Comparisons between two groups were analysed using t-tests. One-way ANOVA was used for comparison of three or more groups, with additional post-hoc Tukey's tests to account for multiple comparisons. Statistical analysis of categorical variables was performed using the $\chi^{2}$ test. Correlations between miR-302c-3p and miR-520a-3p expression levels and CC profile and between miR-302c-3p, miR-520a-3p and CXCL8 expression levels were determined by Pearson's linear correlation analysis. $\mathrm{P}<0.05$ was considered to indicate a statistically significant difference.

\section{Results}

miR-302c-3p and miR-520a-3p are downregulated in $C C$ cell lines. To investigate the potentially dysregulated miRNAs between clinical CC tissues and tumour-adjacent tissues, RT-qPCR was performed to measure the expression of 25 mature miRNA sequences in both CC tissues and tumour-adjacent tissues (Fig. 1A). Two highly downregulated miRNAs, miR-302c-3p and miR-520a-3p, were notable due to their tumour-suppressing roles in other cancer cells $(7,18)$. Furthermore, the expression of miR-302c-3p and miR-520a-3p was examined in 20 pairs of clinical CC tissues and tumour-adjacent normal tissues. The data showed that miR-302c-3p and miR-520a-3p were downregulated in $\mathrm{CC}$ tissues compared with adjacent tissues (Fig. 1B and C; $\left.{ }^{* * *} \mathrm{P}<0.001,{ }^{* *} \mathrm{P}<0.01\right)$. Pearson's linear correlation analysis revealed that miR-302c-3p and miR-520a-3p expression levels in adjacent normal tissues were positively correlated with those in normal tissues (Fig. 1D and $\mathrm{E} ; \mathrm{P}=0.0051, \mathrm{P}=0.0025$ ). The expression levels of miR-302c-3p and miR-520a-3p were measured in two CC cell lines (HeLa-S3 and C-33A), as well as in the immortalized cervical epithelial cell line H8. It was found that miR-302c-3p and miR-520a-3p were both downregulated in HeLa-S3 and C-33A cells (Fig. 1F-G; ${ }^{*} \mathrm{P}<0.05$, $\left.{ }^{* *} \mathrm{P}<0.01,{ }^{* * *} \mathrm{P}<0.001,{ }^{* * * *} \mathrm{P}<0.0001\right)$. These results demonstrate that the expressions of miR-302c-3p and miR-520a-3p are downregulated in both $\mathrm{CC}$ tissues and cell lines.

miR-302c-3p and miR-520a-3p inhibit the proliferation of $C C$. miR-302c-3p is reported to inhibit the growth of hepatocellular carcinoma (20), while miR-520a-3p inhibits the proliferation of non-small cell lung cancer cells (18). To investigate whether miR-302c-3p or miR-520a-3p is involved in the proliferation of CC, CCK-8 and EdU assays were performed using cells transfected with mimics or inhibitors 
A

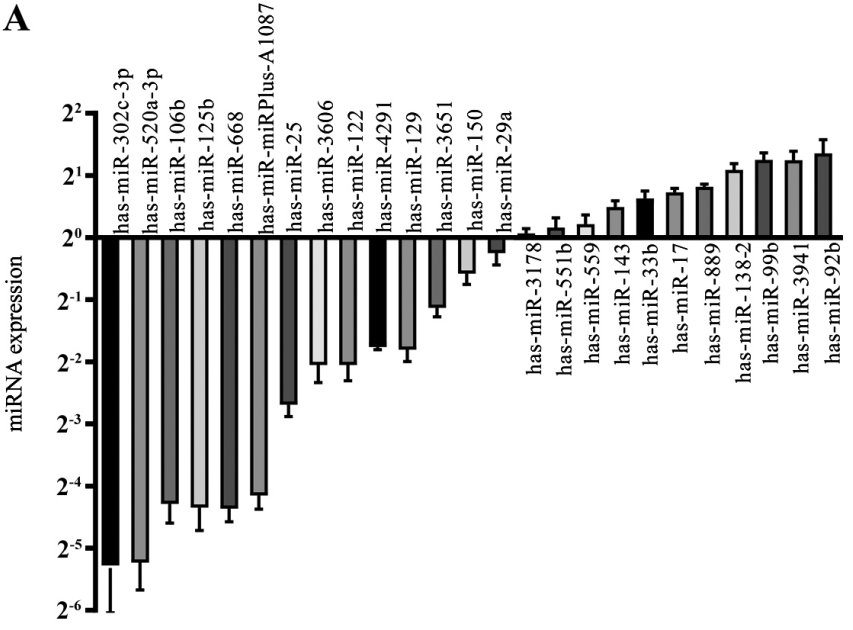

B

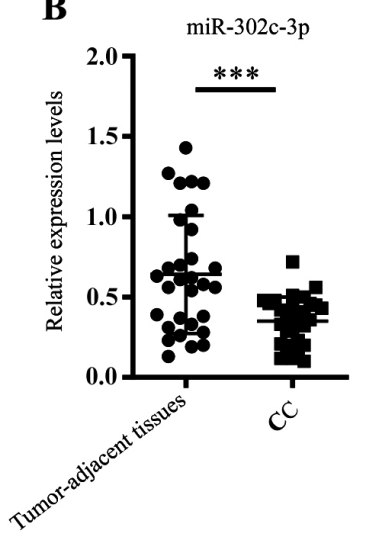

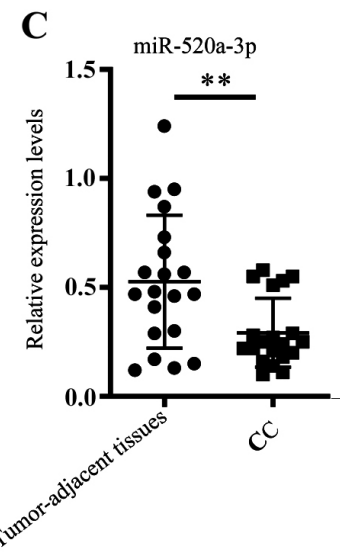

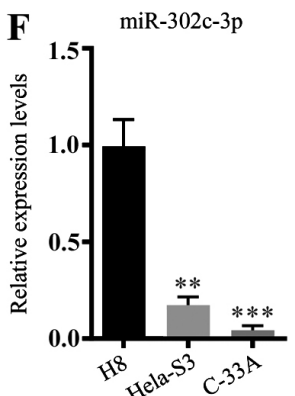

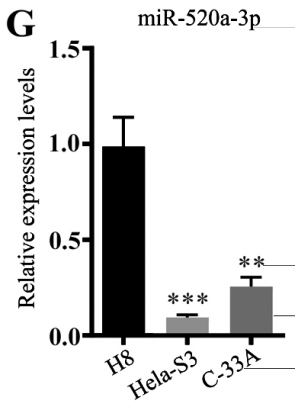

D

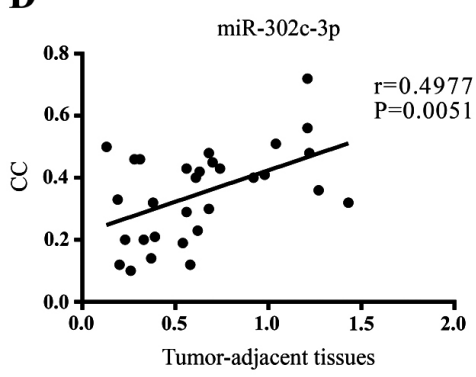

$\mathbf{E}$

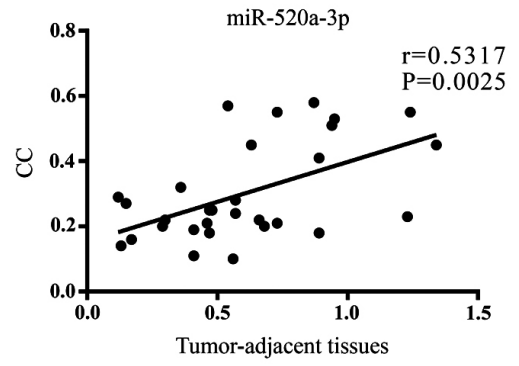

Figure 1. miR-302c-3p and miR-520a-3p are decreased in CC cell lines and clinical CC tissues. (A) Expression profile of 25 mature miRNA sequences in CC tissues and adjacent tissues. (B and C) The relative expression levels of miR-302c-3p and miR-520a-3p in adjacent normal tissues and CC tissues. (D and E) The relation of the expression of miR-302c-3p and miR-520a-3p between CC and tumour-adjacent tissues displayed with correlational analyses. (F and G) The expression of miR-302c-3p and miR-520a-3p in CC cell lines (HeLa-S3 and C-33A) and the normal cervical epithelial cell line H8. Compared with $\mathrm{H} 8$ group. $\mathrm{n}=3 ;{ }^{* *} \mathrm{P}<0.01 ;{ }^{* * *} \mathrm{P}<0.001$. CC, cervical carcinoma; miR, microRNA.

of miR-302c-3p and miR-520a-3p. The transfection efficiency of both overexpression and knockdown of miR-302c-3p and miR-520a-3p were verified using RT-qPCR (Figs. 2A and S1A; $\left.{ }^{* * * *} \mathrm{P}<0.0001\right)$. A significant decrease in cell proliferation was observed in both HeLa-S3 and C-33A cells transfected with miR-302c-3p/miR-520a-3p mimics (Fig. 2B; ${ }^{*} \mathrm{P}<0.05$, ${ }^{* *} \mathrm{P}<0.01$ ), whereas the cells treated with miR-302c-3p and miR-520a-3p inhibitors had increased proliferation (Fig. S1B; ${ }^{* *} \mathrm{P}<0.01$ ) compared with the control groups (blank cells were treated with an equivalent volume of PBS). Co-transfection of miR-302c-3p and miR-520a-3p mimics led to cooperative suppression of cell proliferation, which was greater than that of cells transfected with miR-302c-3p or miR-520a-3p alone. Results consistent with these observations were also obtained from the EdU staining assay (Figs. $2 \mathrm{C}$ and $\mathrm{S} 1 \mathrm{C} ;{ }^{* *} \mathrm{P}<0.01$, $\left.{ }^{* * * * *} \mathrm{P}<0.0001,{ }^{*} \mathrm{P}<0.05\right)$. Tumour tissue growth requires the rate of cell proliferation to exceed that of cell death; thus, the apoptosis-associated functions of miR-302c-3p and miR-520a-3p were detected using flow cytometry. As expected, both HeLa-S3 and $\mathrm{C}-33 \mathrm{~A}$ cells (Fig. $2 \mathrm{D} ;{ }^{* *} \mathrm{P}<0.01,{ }^{* * * *} \mathrm{P}<0.0001$ ) transfected with $\mathrm{miR}-302 \mathrm{c}-3 \mathrm{p} / \mathrm{miR}-520 \mathrm{a}-3 \mathrm{p}$ mimics showed significant increases in cell apoptosis, whereas the cells treated with miR-302c-3p/miR-520a-3p inhibitor showed decreases in cell apoptosis (Fig. S1D; ${ }^{* *} \mathrm{P}<0.01,{ }^{* * * *} \mathrm{P}<0.0001$ vs. control). These results demonstrated that miR-302c-3p and miR-520a-3p can suppress the growth and promote the apoptosis of $\mathrm{CC}$ cells in an independent or cooperative manner.
CXCL8 is a direct target of $m i R-302 c-3 p$ and $m i R-520 a-3 p$. To understand the proliferation-suppressive role of miR-302c-3p and miR-520a-3p, the potential target genes of miR-302c-3p and miR-520a-3p were predicted by using miRTarBase. Among the candidates, CXCL8 has been reported to be upregulated in various types of carcinomas $(21,22)$ and contributes to cancer cell proliferation $(23,24)$. Therefore, CXCL8 was selected for further evaluation and RT-qPCR demonstrated that CC tissues had much higher CXCL8 expression than tumour-adjacent tissues (Fig. 3A; $\left.{ }^{* * * *} \mathrm{P}<0.0001\right)$. Pearson's linear correlation analysis found that CXCL8 was negatively correlated with miR-302c-3p and miR-520a-3p (Fig. 3B; $\mathrm{P}=0.0002, \mathrm{P}=0.0065$ ). Moreover, RT-qPCR measured the relative expressions of CXCL8 and miR-302c-3p/miR-520a-3p, which showed that high expression of miR-302c-3p or miR-520a-3p corresponds to low expression of CXCL8 (Fig. S2A; ${ }^{* *} \mathrm{P}<0.01$ ). RT-qPCR and western blot analysis revealed that the mRNA and protein expression levels of CXCL8 were increased in HeLa-S3 and C-33A cells compared with H8 cells (Fig. 3C; $\left.{ }^{* *} \mathrm{P}<0.01,{ }^{* * *} \mathrm{P}<0.001\right)$. To investigate whether miR-302c-3p and miR-520a-3p regulate CXCL8 expression in CC cells, HeLa-S3 and C-33A cells were transfected with miR-302c-3p and miR-520a-3p mimics before measurement of CXCL8 expression. CXCL8 was downregulated in response to transfection of miR-302c-3p and miR-520a-3p mimics into CC cells (Fig. 3D and $\left.\mathrm{E} ;{ }^{*} \mathrm{P}<0.05,{ }^{* *} \mathrm{P}<0.01\right)$. Furthermore, a luciferase reporter assay was performed to identify the binding of CXCL8 
A

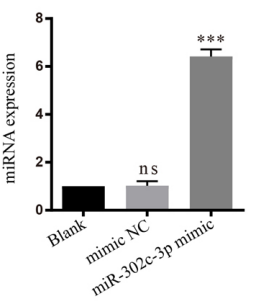

miR-302c-3p

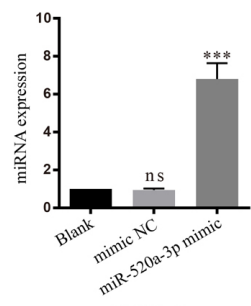

miR-520a-3p

HeLa-S3

B

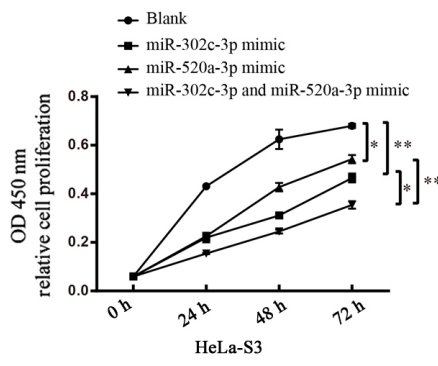

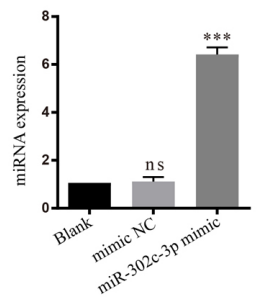

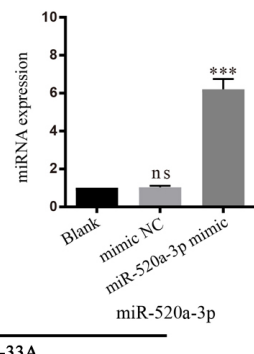

C-33A

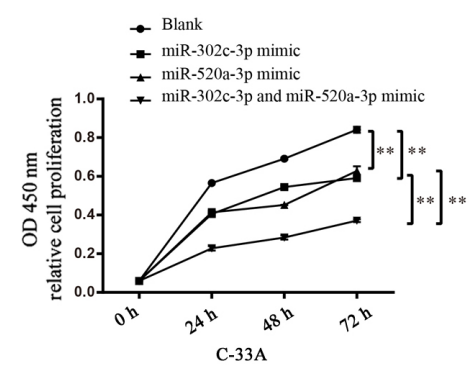

C

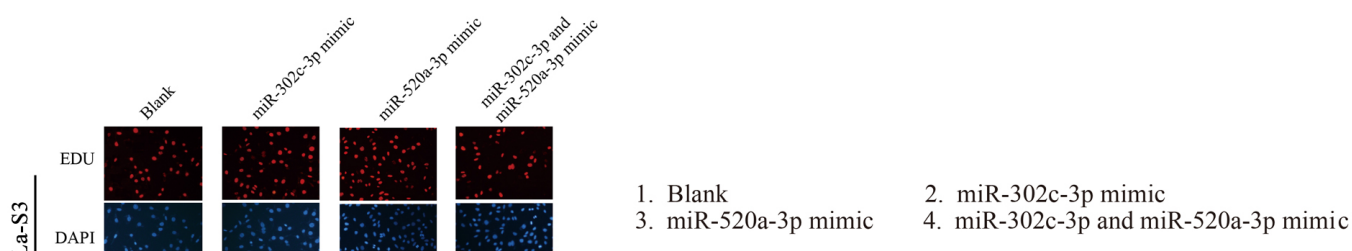

3. miR-520a-3p mimic 4. miR-302c-3p and miR-520a-3p mimic

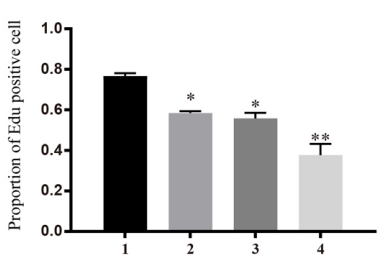

HeLa-S3

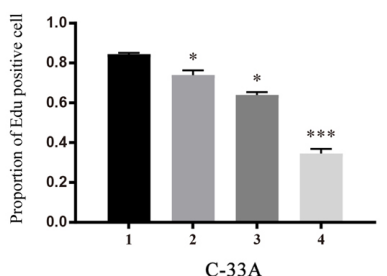

and

D
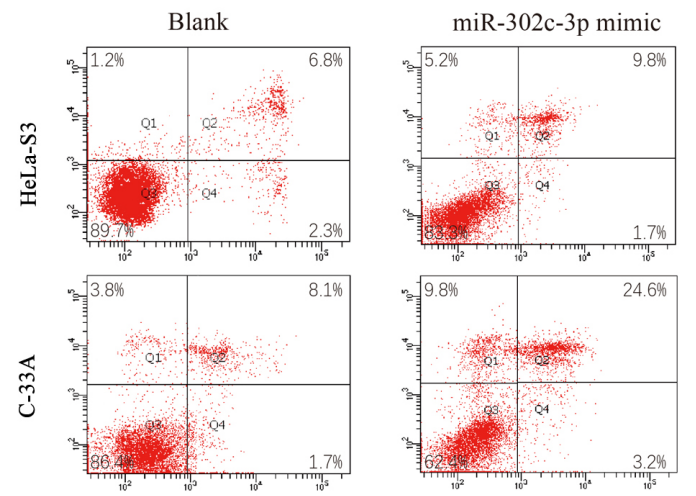

1. Blank

2. miR-302c-3p mimic

4. miR-302c-3p and miR-520a-3p mimic
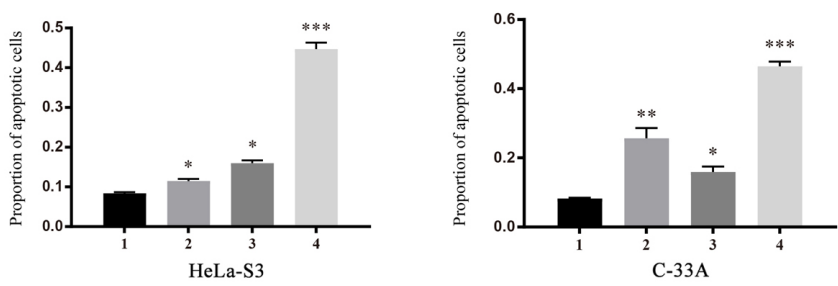
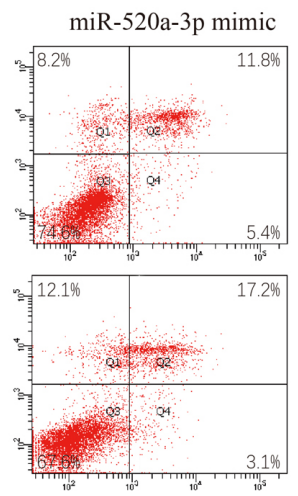

3.1.1\%

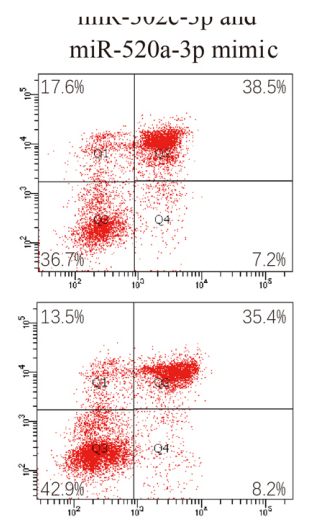

Figure 2. Downregulation of miR-302c-3p and miR-520a-3p increases proliferation and decreases apoptosis in CC cells. (A) Reverse transcription-quantitative polymerase chain reaction assays to detect the transfection efficiencies of miR-302c-3p and miR-520a-3p mimics, and mimic NC represents mimic control. Compared with blank group. (B) Cell Counting Kit-8 assays of HeLa-S3 (left) and C-33A (right) cell proliferation after transfection with miR-302c-3p/miR-520a-3p mimics. (C) Changes in CC cell proliferation were also determined by EdU staining (EdU/DAPI). Decreased cell proliferation by upregulating miR-302c-3p or/and miR-520a-3p was observed in HeLa-S3 (top) and C-33A (bottom) cells. Compared with mimic NC group. 'miR-302c-3p mimic' vs. 'miR-302c-3p and miR-520a-3p': P<0.05 (HeLa-S3), P<0.01 (C-33A); 'miR-520a-3p mimic' vs. 'miR-302c-3p and miR-520a-3p': P<0.01 (HeLa-S3), $\mathrm{P}<0.001$ (C-33A). (D) The changes in apoptosis of CC cells were determined by flow cytometry. 'miR-302c-3p mimic' or 'miR-520a-3p' vs. 'miR-302c-3p and miR-520a-3p': $\mathrm{P}<0.001 .{ }^{*} \mathrm{P}<0.05 ;{ }^{* *} \mathrm{P}<0.01 ;{ }^{* * *} \mathrm{P}<0.001 . \mathrm{CC}$, cervical carcinoma; miR, microRNA. 
A

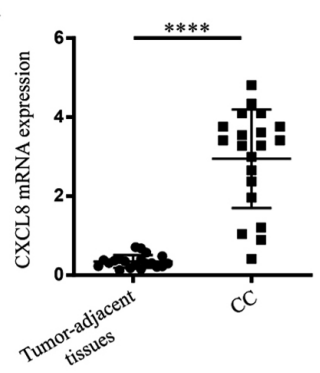

D

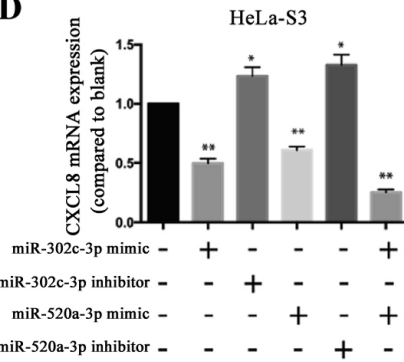

$\mathbf{F}$
B

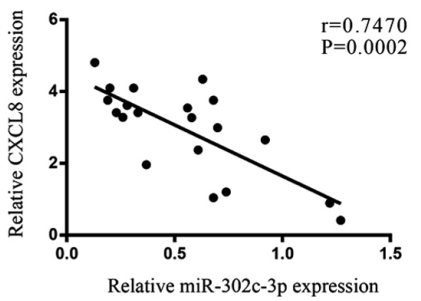

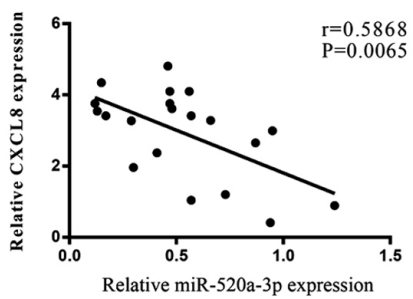

C

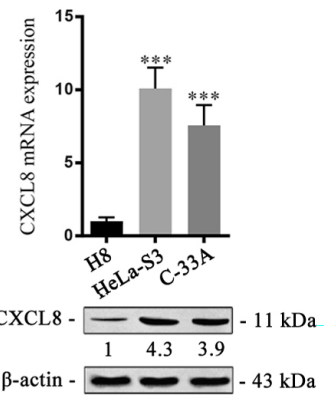

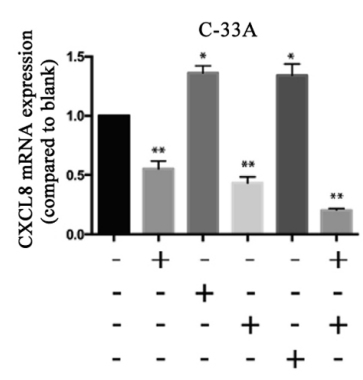

$\mathbf{E}$

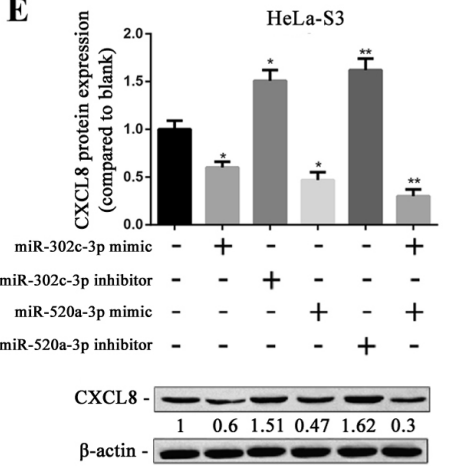

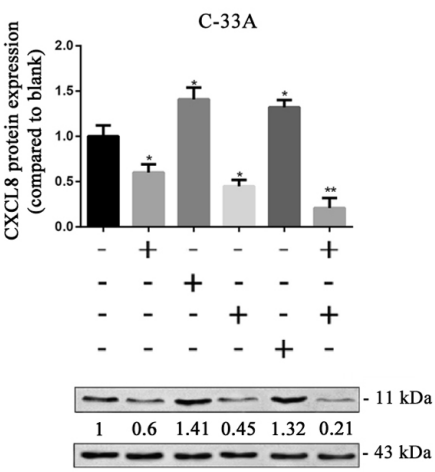

C-33A
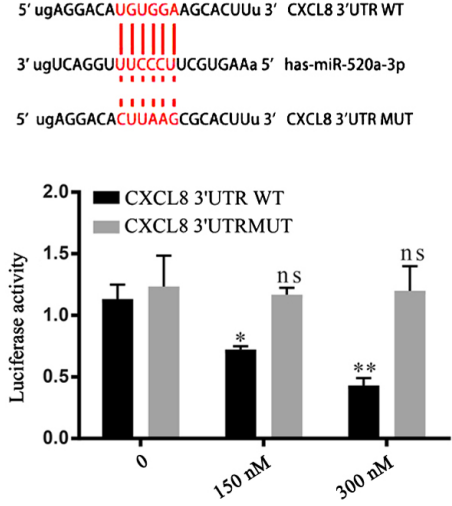

miR-520a-3p mimic

Figure 3. CXCL8 is a common target gene of miR-302c-3p and miR-520a-3p. (A) Expression levels of CXCL8 in tumour-adjacent and CC tissues were detected by reverse transcription-quantitative polymerase chain reaction. (B) Association between expression levels of CXCL8 and miR-302c-3p or miR-520a-3p was displayed with correlational analyses. (C) mRNA (top) and protein (bottom) expression levels of CXCL8 in CC cell lines (HeLa-S3 and C-33A cells) and normal cervical epithelial cells. The mRNA (D) and protein (E) expression level of CXCL8 in HeLa-S3 and C-33A cells after transfection with miR-302c-3p/miR-520a-3p mimics compared to blank cells. 'miR-302c-3p mimic' vs. 'miR-302c-3p and miR-520a-3p': P<0.05 (HeLa-S3), P<0.05 (C-33A); 'miR-520a-3p mimic' vs. 'miR-302c-3p and miR-520a-3p': P<0.05 (HeLa-S3), P<0.05 (C-33A), the values represent the gray values of the western blotting bands. (F) Diagram of the CXCL8 3'-UTR-containing reporter construct. Representative luciferase activity in 293T cells co-transfected with wild-type or mutated reporter plasmids and miR-302c-3p or miR-520a-3p mimics. ${ }^{*} \mathrm{P}<0.05 ;{ }^{* *} \mathrm{P}<0.01 ;{ }^{* * *} \mathrm{P}<0.001 ;{ }^{* * * *} \mathrm{P}<0.0001$. CC, cervical carcinoma; miR, microRNA; CXCL8, C-X-C motif ligand 8.

with $\mathrm{miR}-302 \mathrm{c}-3 \mathrm{p}$ or miR-520a-3p. The results revealed that miR-302c-3p mimics and miR-520a-3p mimics inhibited the luciferase reporter activity of the wild-type CXCL8 3'-UTR construct (Fig. 3F; ${ }^{* *} \mathrm{P}<0.01$ ). Collectively, these data indicated that CXCL8 is a direct common target of miR-302c-3p and miR-520a-3p.

CXCL8 promotes the proliferation and decreases the apoptosis of CC cells. As previously described, CXCL8 has been reported to be involved in cell proliferation-promoting and apoptosis-suppressive behaviour in cancerous cells $(23,24)$. To investigate whether CXCL8 is a tumour-related cytokine in HeLa-S3 and C-33A cells, the effect of CXCL8 on CC cell proliferation was detected by the CCK-8 assay. Briefly, the HeLa-S3 and C-33A cell lines were treated with CXCL8 siRNA or negative control (NC) or with pcDNA3.1-CXCL8 or pcDNA3.1, and then both CCK-8 and EdU staining assays were performed. Compared with the levels in cells treated with si-NC, the mRNA and protein levels of CXCL8 were decreased in cells transfected with si-CXCL8, whereas cells treated with pcDNA3.1-CXCL8 (pcDNA3.1 used as control) showed increased expression (Fig. $4 \mathrm{~A} ;{ }^{* *} \mathrm{P}<0.01$ ). The up- and downregulation of CXCL8 correspondingly increased or decreased the proliferation ability of HeLa-S3 and C-33A cells compared with the controls (Figs. $4 \mathrm{~B}$ and $\mathrm{C}$ and $\mathrm{S} 3 \mathrm{~A}$; ${ }^{*} \mathrm{P}<0.05$, $\left.{ }^{* * * * *} \mathrm{P}<0.0001\right)$. To investigate whether CXCL8 can decrease CC cell apoptosis, flow cytometry was also performed. A significant decrease in apoptosis was observed in both HeLa-S3 and 
A

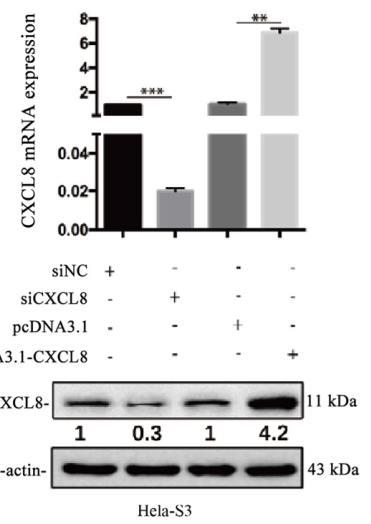

C

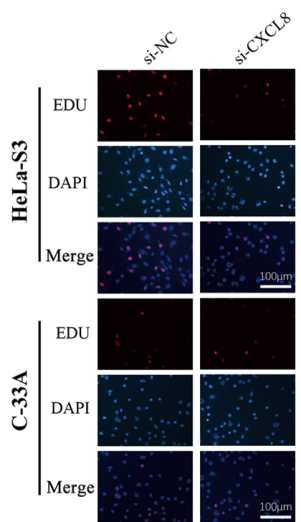

D
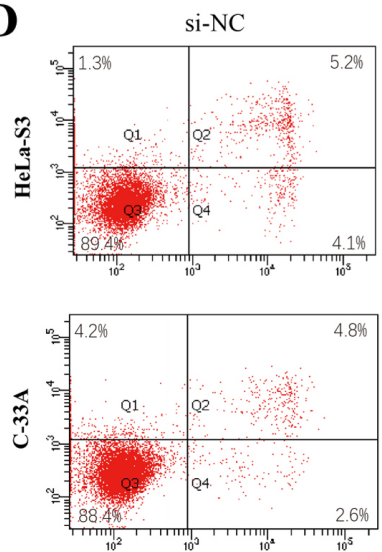
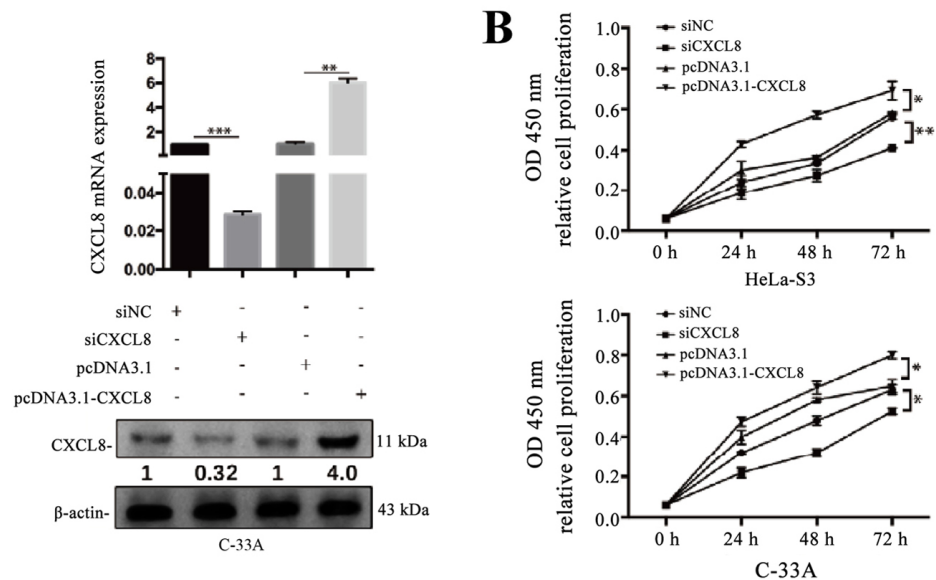
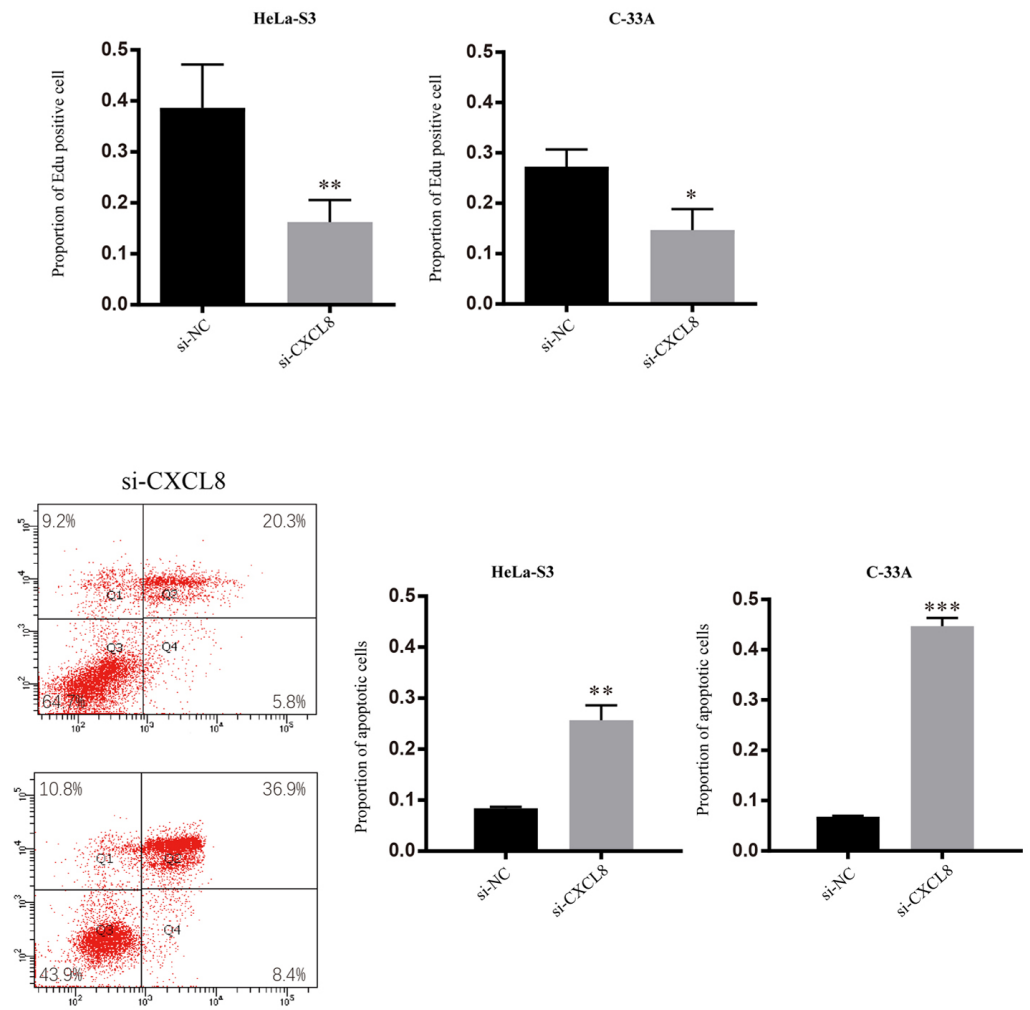

Figure 4. CXCL8 promotes proliferation and suppresses apoptosis in CC cells. (A) mRNA and protein expression levels of CXCL8 in HeLa-S3 cells and C-33A cells after transfection with si-NC and CXCL8 siRNA (si-CXCL8), pcDNA3.1 and pcDNA3.1-CXCL8, which were compared with si-NC group or pcDNA3.1 group, respectively. (B) Proliferation of HeLa-S3 and C-33A cells in response to transfection of CXCL8 siRNA or pcDNA3.1-CXCL8 or negative control plasmid. (C) EdU assay of HeLa-S3 and C-33A cells transfected with CXCL8 siRNA. Graph shows the proportion of EdU positive cells (EdU/DAPI). (D) Flow cytometry was used to determine the apoptosis of HeLa-S3 and C-33A cells transfected with CXCL8 siRNA. CXCL8 siRNA was compared with si-NC. ${ }^{*} \mathrm{P}<0.05 ;{ }^{* * *} \mathrm{P}<0.01 ;{ }^{* * *} \mathrm{P}<0.001$. CC, cervical carcinoma; CXCL8, C-X-C motif ligand 8; si-NC, siRNA control.

C-33A cells transfected with pcDNA3.1-CXCL8, whereas the cells treated with si-CXCL8 showed the opposite effects (Figs. 4D and S3B; ${ }^{* * *} \mathrm{P}<0.001,{ }^{* * * *} \mathrm{P}<0.0001$ ).

Downregulation of CXCL8 by miR-302c-3p and miR-520a-3p inhibits $C C$ cell proliferation. To confirm whether CXCL8 downregulation is the mechanism by which miR-302c-3p and miR-520a-3p suppress proliferation and promote apoptosis in CC cells, HeLa-S3 and C-33A cells were co-transfected with pcDNA3.1-CXCL8 or pcDNA3.1 and miR-302c-3p/miR-520a-3p mimics. As expected, restoration of CXCL8 partially blocked the miR-302c-3p and miR-520a-3p-mediated suppression of $\mathrm{CC}$ cell proliferation and promotion of apoptosis (Figs. $5 \mathrm{~A}$ and $\mathrm{B}$ and $6 ;{ }^{* *} \mathrm{P}<0.01$, $\left.{ }^{* * *} \mathrm{P}<0.001,{ }^{* * * *} \mathrm{P}<0.0001,{ }^{*} \mathrm{P}<0.05\right)$. In summary, these results indicated that CXCL8 is a functional target of miR-302c-3p and $\mathrm{miR}-520 \mathrm{a}-3 \mathrm{p}$ to suppress the proliferation of CC cells.

\section{Discussion}

To the author's best knowledge, the ability of miR-302c-3p and miR-520a-3p to efficiently target CXCL8 and thus 
A
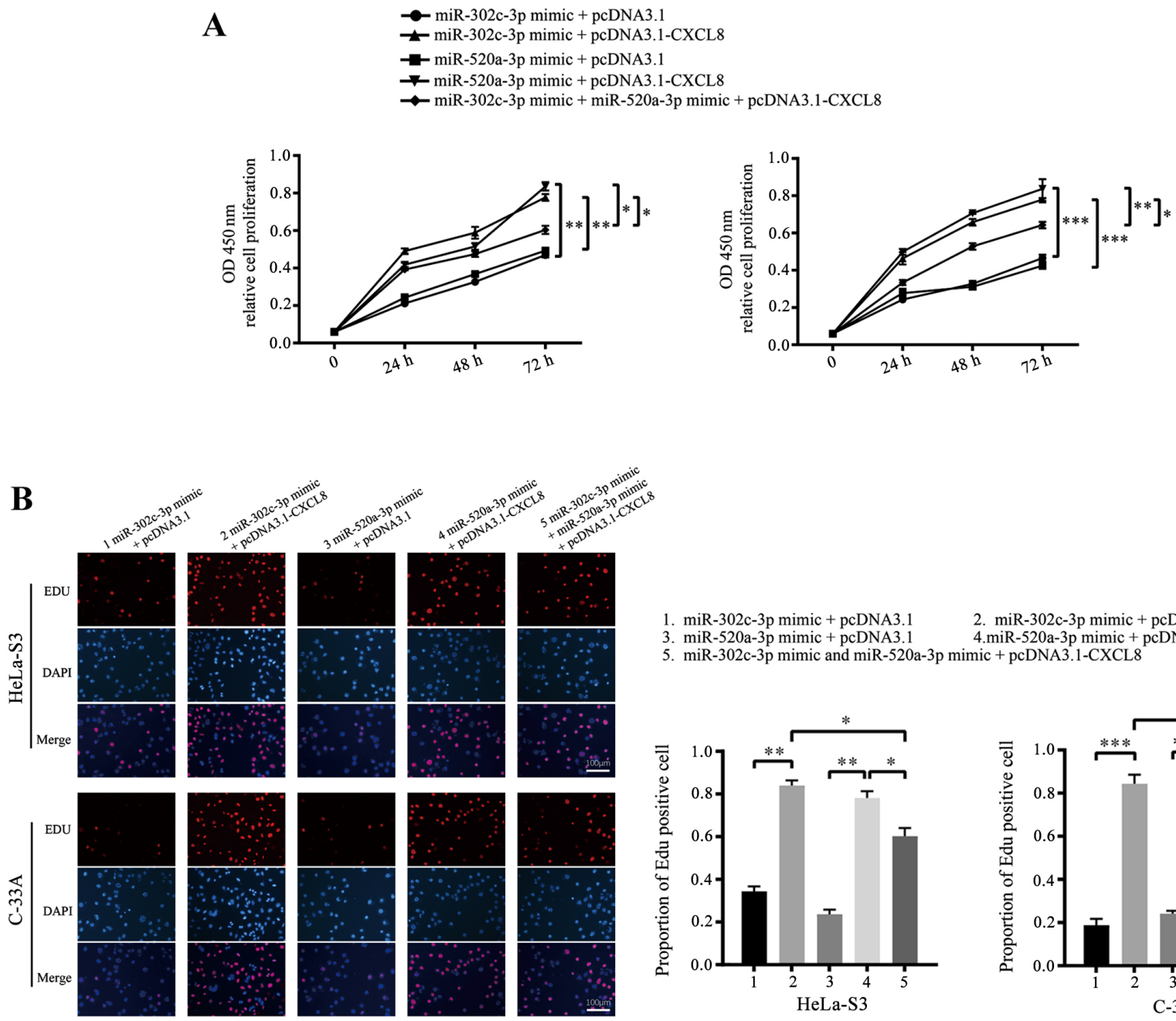

$\begin{array}{ll}\text { 1. miR-302c-3p mimic + pcDNA3.1 } & \text { 2. miR-302c-3p mimic + pcDNA3.1-CXCL8 } \\ \text { 3. miR-520a-3p mimic + pcDNA3.1 } & \text { 4.miR-520a-3p mimic + pcDNA3.1-CXCL8 }\end{array}$

5. $\mathrm{miR}-302 \mathrm{c}-3 \mathrm{p}$ mimic and miR-520a-3p mimic + pcDNA3.1-CXCL8
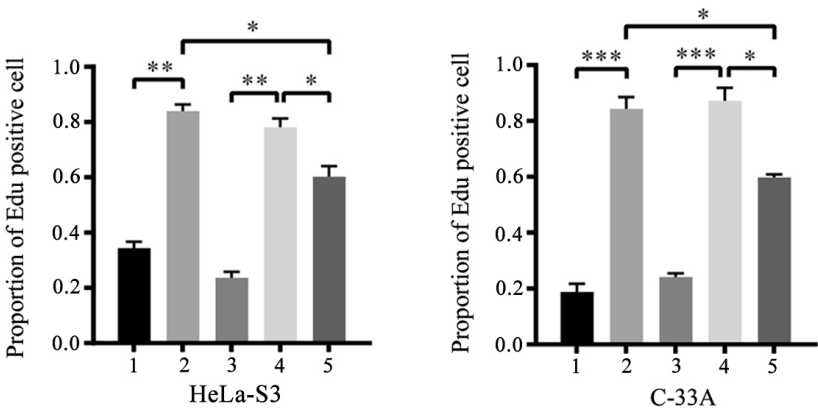

Figure 5. CXCL8 blocks the proliferation-suppressive effects of miR-302c-3p and miR-520a-3p in CC cell lines. (A) Cell counting kit-8 assay of HeLa-S3 and C-33A cells co-transfected with miR-302c-3p/miR-520a-3p mimics and/or CXCL8 plasmid. (B) EdU assays of HeLa-S3 (top) and C-33A (bottom) cells co-transfected with miR-302c-3p/miR-520a-3p mimics or CXCL8 plasmid. Graph shows the proportion of EdU positive cells. " $\mathrm{P}<0.05 ;{ }^{* * *} \mathrm{P}<0.01$; ${ }^{* * * *} \mathrm{P}<0.001$. CC, cervical carcinoma; miR, microRNA; CXCL8, C-X-C motif ligand 8.
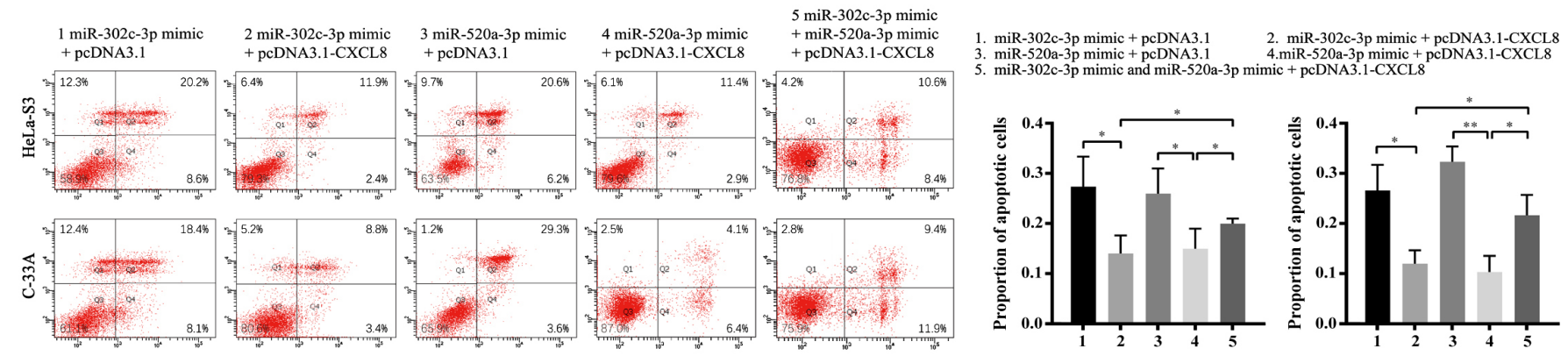

Figure 6. CXCL8 blocks the apoptosis-promoting effects of miR-302c-3p and miR-520a-3p in CC cell lines. Flow cytometry shows the efficacy of pcDNA3.1-CXCL8 in restoring the proliferation-promoting and apoptosis-suppressive function in HeLa-S3 and C-33A cells. CXCL8 siRNA and pcDNA3.1-CXCL8 were compared with si-NC and pcDNA3.1, respectively. Cells co-transfected with miR-302c-3p mimic, miR-520a-3p mimic and pcDNA3.1-CXCL8 were compared with miR-302c-3p mimic and pcDNA3.1 as well as miR-520a-3p mimic and pcDNA3.1. "P<0.05; ${ }^{* *} \mathrm{P}<0.01$. CC, cervical carcinoma; miR, microRNA; si-NC, siRNA control; CXCL8, C-X-C motif ligand 8.

modulate the proliferation of $\mathrm{CC}$ cells has not been reported before. Although previous studies have revealed that miR-302c-3p can suppress cell proliferation in glioma (7), renal cell carcinoma (8) and hepatocellular carcinoma (9), and miR-520a-3p can suppress cell proliferation in non-small cell lung cancer (18), breast cancer (25) and osteosarcoma (26), the functions of miR-302c-3p and miR-520a-3p in CC are still unknown. In the present study, the expression of miR-302c-3p and miR-520a-3p was measured in CC tissues and adjacent tissues, which revealed that both of these miRs were 
downregulated in CC cells and tissues. Transfection of $\mathrm{CC}$ cells demonstrated that miR-302c-3p and miR-520a-3p could inhibit the proliferation and enhance the apoptosis of CC cells. These results show that miR-302c-3p and miR-520a-3p are important proliferation suppressors and apoptosis promoters in $\mathrm{CC}$.

CXCL8 is upregulated in a variety of solid tumours, including gastric cancer (21), ovarian cancer (27), non-small cell lung cancer (28) and breast cancer (29) and is reported to be relevant to a broad spectrum of biological behaviours of cancer cells, such as increased proliferation (30), invasion (31) and metastasis (32). In addition, CXCL8 has also been reported to be associated with the severity of cervical cancer malignancy $(33,34)$. It has been reported that inhibition of CXCL8 is associated with inhibition of angiogenesis in CC (35). Overexpression of CXCL8 can increase the proliferation and survival of cancer cells through autocrine signalling pathways: MAPK $(36,37)$, focal adhesion kinase and sarcoma signalling (38). Queries about the function of CXCL8 in CC, together with the evidence of the proliferation-promoting activity of CXCL8 in other carcinomas, prompted further investigation of this predicted target gene of miR-302c-3p and miR-520a-3p. In the present study, it was found that CXCL8 is upregulated both in CC cells and clinical CC tissues. Knockdown of CXCL8 attenuated the proliferation and increased the apoptosis of HeLa-S3 and C-33A cells. Importantly, CXCL8 is directly targeted by miR-302c-3p and miR-520a-3p, and the inhibition of cell proliferation induced by miR-302c-3p and miR-520a-3p can be abrogated by CXCL8 overexpression in CC cell lines.

The findings of the present study provide direct evidence that the downregulation of CXCL8 induced by miR-302c-3p and miR-520a-3p results in decreased proliferation and increased apoptosis activity in CC cells. Specifically, it was found that miR-302c-3p and miR-520a-3p synergistically downregulated CXCL8. Members of the primate-specific miRNA family, miR-302c-3p and miR-520-3p share similar seed sequences. Accumulating evidence has indicated that miRNAs may target multiple genes in a coordinated way. Therefore, only a subset of collaborating miRNAs can be identified on the basis of miRNA expression analysis. To explore the full interaction of miRNAs, a more efficient screening method should be performed; however, methods for such studies are currently unavailable. The present study was limited in several aspects, as relevant data concerning migration, invasion and angiogenesis in $\mathrm{CC}$ were missing. However, this can be a direction for future work to explore the possible role of both miR-302c-3p and miR-520a-3p in CC.

There are several limitations that are noteworthy. Firstly, in the present study, expression of CXCL8 was lower in C33A cells compared with that in Hela-S3 cells. However, TCGA data show that HPV-positive cases, e.g., Hela cells derived from HPV-positive adenocarcinoma cells, have decreased expression of CXCL8 compared to HPV-negative cases, e.g., C-33A cells derived from HPV-negative squamous cell carcinoma cells. This discrepancy may possibly arise due to the varieties and differences between tumor samples and cell lines in TCGA data. Considering the discrepancy, further measurements and analysis on the expression of CXCL8 among CC cells can form a future study. Secondly, it has been reported that inhibition of
CXCL8 is associated with inhibition of angiogenesis (37). In the present study, the effect of miR-302c-3p and miR-520a-3p on proliferation and apoptosis of CC cells was the main focus. Although no related data concerning angiogenesis was mentioned, this could serve as the future direction for study. Moreover, although no relevant data concerning the migration and invasion of CC cells is presented it is a promising direction for future research.

The present study demonstrated that miR-302c-3p and miR-520a-3p were downregulated in CC cell lines and clinical $\mathrm{CC}$ tissues. Furthermore, the overexpression of miR-302c-3p and miR-520a-3p suppressed CC cell proliferation and promoted CC cell apoptosis in vitro by targeting CXCL8. The miR-302c/520a-CXCL8 axis deepens the understanding of the mechanisms underlying the proliferation of tumour cells and may provide a potential therapeutic strategy for the targeted treatment of CC. Furthermore, as many studies have documented that CXCL8 is overexpressed in a large set of diseases in advanced stages, suppressing the effects of CXCL8 may have important implications for the systemic treatment of aggressive and metastatic diseases.

\section{Acknowledgements}

Not applicable.

\section{Funding}

This work was supported by the National Natural Science Foundation of China (grant no. 81672560).

\section{Availability of data and materials}

The datasets used and/or analyzed during the current study are available from the corresponding author on reasonable request.

\section{Authors' contributions}

HMD, HZ and YGC conceptualized the study and designed the experiments. JW and JHZ performed the experiments. FRS, RNJ and JYS analyzed the data. HMD, HZ and JYS provided critical materials. HMD, HZ and JYS wrote the manuscript. YGC supervised the study. All authors read and approved the final manuscript.

\section{Ethics approval and consent to participate}

Written informed consent was obtained from all patients prior to the experiment. The protocols were approved by the local ethics committee of The First Affiliated Hospital of Soochow University (approval no. SH20181203).

\section{Patient consent for publication}

Not applicable.

\section{Competing interests}

The authors declared that they have no competing interests. 


\section{References}

1. DiPaolo JA and Alvarez-Salas LM: Advances in the development of therapeutic nucleic acids against cervical cancer. Expert Opin Biol Ther 4: 1251-1264, 2004.

2. Torre LA, Bray F, Siegel RL, Ferlay J, Lortet-Tieulent J and Jemal A: Global cancer statistics, 2012. CA Cancer J Clin 65 87-108, 2015.

3. Bartel DP: MicroRNAs: Genomics, biogenesis, mechanism, and function. Cell 116: 281-297, 2004.

4. Zhang J, Bai R, Li M, Ye H, Wu C, Wang C, Li S, Tan L, Mai D, Li G, et al: Excessive miR-25-3p maturation via N6-methyladenosine stimulated by cigarette smoke promotes pancreatic cancer progression. Nat Commun 10: 1858, 2019.

5. Frank AC, Ebersberger S, Fink AF, Lampe S, Weigert A, Schmid T, Ebersberger I, Syed SN and Brüne B: Apoptotic tumor cell-derived microRNA-375 uses CD36 to alter the tumor-associated macrophage phenotype. Nat Commun 10: 1135, 2019.

6. Chen Z, Zeng H, Guo Y, Liu P, Pan H, Deng A and Hu J: miRNA-145 inhibits non-small cell lung cancer cell proliferation by targeting c-Myc. J Exp Clin Cancer Res 29: 151, 2010.

7. Wang Y, Wei Y, Tong H, Chen L, Fan Y, Ji Y, Jia W, Liu D and Wang G: miR-302c-3p suppresses invasion and proliferation of glioma cells via down-regulating metadherin (MTDH) expression. Cancer Biol Ther 16: 1308-1315, 2015

8. Gu DH, Mao JH, Pan XD, Zhu H, Chen X, Zheng B and Shan Y: microRNA-302c-3p inhibits renal cell carcinoma cell proliferation by targeting Grb2-associated binding 2 (Gab2). Oncotarget 8 : 26334-26343, 2017.

9. Yang L, Guo Y, Liu X, Wang T, Tong X, Lei K, Wang J, Huang D and $\mathrm{Xu}$ Q: The tumor suppressive miR-302c-3p inhibits migration and invasion of hepatocellular carcinoma cells by targeting TRAF4. J Cancer 9: 2693-2701, 2018

10. Min D, Lv XB, Wang X, Zhang B, Meng W, Yu F and $\mathrm{Hu} \mathrm{H}$ : Downregulation of miR-302c and miR-520c by $1,25(\mathrm{OH}) 2 \mathrm{D} 3$ treatment enhances the susceptibility of tumour cells to natural killer cell-mediated cytotoxicity. Br J Cancer 109: 723-730, 2013.

11. Liu Q, Li A, Tian Y, Wu JD, Liu Y, Li T, Chen Y, Han X and Wu K: The CXCL8-CXCR1/2 pathways in cancer. Cytokine Growth Factor Rev 31: 61-71, 2016.

12. Jia L, Li F, Shao M, Zhang W, Zhang C, Zhao X, Luan H, Qi Y, Zhang P, Liang L, et al: IL-8 is upregulated in cervical cancer tissues and is associated with the proliferation and migration of HeLa cervical cancer cells. Oncol Lett 15: 1350-1356, 2018.

13. Sanguinete MMM, Oliveira PH, Martins-Filho A, Micheli DC, Tavares-Murta BM, Murta EFC and Nomelini RS: Serum IL-6 and IL-8 correlate with prognostic factors in ovarian cancer. Immunol Invest 46: 677-688, 2017.

14. Yung MM, Tang HW, Cai PC, Leung TH, Ngu SF, Chan KK, Xu D, Yang H, Ngan HY and Chan DW: GRO- $\alpha$ and IL- 8 enhance ovarian cancer metastatic potential via the CXCR2-mediated TAK1/NFKB signaling cascade. Theranostics 8: 1270-1285, 2018.

15. Qu J, Cheng T, Liu L, Heng J, Liu X, Sun Z, Wang W, Li K and Yang N: Mast cells induce epithelial-to-mesenchymal transition and migration in non-small cell lung cancer through IL-8/Wnt/beta-catenin pathway. J Cancer 10: 5567, 2019.

16. Tang CP,Zhou HJ, Qin J, Luo Y and Zhang T: MicroRNA-520c-3p negatively regulates EMT by targeting IL- 8 to suppress the invasion and migration of breast cancer. Oncol Rep 38: 3144-3152, 2017.

17. Mei Q, Xue G, Li X, Wu Z, Li X, Yan H, Guo M, Sun S and Han W: Methylation-induced loss of miR-484 in microsatellite-unstable colorectal cancer promotes both viability and IL-8 production via CD137L. J Pathol 236: 165-174, 2015.

18. Yu J, Tan Q, Deng B, Fang C, Qi D and Wang R: The microRNA-520a-3p inhibits proliferation, apoptosis and metastasis by targeting MAP3K2 in non-small cell lung cancer. Am J Cancer Res 5: 802-811, 2015.

19. Livak KJ and Schmittgen TD: Analysis of relative gene expression data using real-time quantitative PCR and the 2(-Delta Delta C(T)) method. Methods 25: 402-408, 2001.

20. Zhu K, Pan Q, Jia LQ, Dai Z, Ke AW, Zeng HY, Tang ZY, Fan J and Zhou J: miR-302c inhibits tumor growth of hepatocellular carcinoma by suppressing the endothelial-mesenchymal transition of endothelial cells. Sci Rep 4: 5524, 2014.
21. Lin C, He H, Liu H, Li R, Chen Y, Qi Y, Jiang Q, Chen L, Zhang P, Zhang H, et al: Tumour-associated macrophages-derived CXCL8 determines immune evasion through autonomous PD-L1 expression in gastric cancer. Gut 68: 1764-1773, 2019.

22. Jayatilaka H, Tyle P, Chen JJ, Kwak M, Ju J, Kim HJ, Lee JSH, Wu PH, Gilkes DM, Fan R and Wirtz D: Synergistic IL-6 and IL-8 paracrine signalling pathway infers a strategy to inhibit tumour cell migration. Nat Commun 8: 15584, 2017.

23. Li MQ,Luo XZ, Meng YH, Mei J,Zhu XY, Jin LP and Li DJ: CXCL8 enhances proliferation and growth and reduces apoptosis in endometrial stromal cells in an autocrine manner via a CXCR1-triggered PTEN/AKT signal pathway. Hum Reprod 27: 2107-2116, 2012.

24. Zhu YM, Webster SJ, Flower D and Woll PJ: Interleukin-8/CXCL8 is a growth factor for human lung cancer cells. Br J Cancer 91: 1970-1976, 2004

25. Li J, Wei J, Mei Z, Yin Y, Li Y, Lu M and Jin S: Suppressing role of miR-520a-3p in breast cancer through CCND1 and CD44. Am J Transl Res 9: 146-154, 2017.

26. Wang X, Xu Y, Chen X and Xiao J: [ARTICLE WITHDRAWN] Dexmedetomidine inhibits osteosarcoma cell proliferation and migration, and promotes apoptosis by regulating miR-520a-3p. Oncol Res 26: 495-502, 2018

27. Shathasivam P, Kollara A, Spybey T, Park S, Clarke B, Ringuette MJ and Brown TJ: VEPH1 expression decreases vascularisation in ovarian cancer xenografts and inhibits VEGFA and IL8 expression through inhibition of AKT activation. Br J Cancer 116: 1065-1076, 2017.

28. Wang S, Campbell J, Stenmark MH, Zhao J, Stanton P, Matuszak MM, Ten Haken RK and Kong FS: Plasma levels of IL- 8 and TGF- $\beta 1$ predict radiation-induced lung toxicity in non-small cell lung cancer: A validation study. Int J Radiat Oncol Biol Phys 98: 615-621, 2017.

29. Wang Y, Liu J, Jiang Q, Deng J, Xu F, Chen X, Cheng F, Zhang Y, Yao Y, Xia Z, et al: Human adipose-derived mesenchymal stem cell-secreted CXCL1 and CXCL8 facilitate breast tumor growth by promoting angiogenesis. Stem Cells 35: 2060-2070, 2017.

30. Cheng J, Li Y, Liu S, Jiang Y, Ma J, Wan L, Li Q and Pang T: CXCL8 derived from mesenchymal stromal cells supports survival and proliferation of acute myeloid leukemia cells through the PI3K/AKT pathway. FASEB J 33: 4755-4764, 2019.

31. Li X, Wang Y, Wei P, Shi D, Wen S, Wu F, Liu L, Ye N and Zhou H: Bisphenol A affects trophoblast invasion by inhibiting CXCL8 expression in decidual stromal cells. Mol Cell Endocrinol 470: 38-47, 2018

32. Tong H, Ke JQ, Jiang FZ, Wang XJ, Wang FY, Li YR, Lu W and Wan XP: Tumor-associated macrophage-derived CXCL8 could induce ER $\alpha$ suppression via HOXB13 in endometrial cancer. Cancer Lett 376: 127-136, 2016.

33. Osiagwu DD, Azenabor AE, Osijirin AA, Awopetu PI and Oyegbami FR: Evaluation of interleukin 8 and interleukin 10 cytokines in liquid based cervical cytology samples. Pan Afr Med J 32: 148, 2019.

34. Yan R, Shuai H, Luo X, Wang X and Guan B: The clinical and prognostic value of CXCL8 in cervical carcinoma patients: Immunohistochemical analysis. Biosci Rep 37: BSR20171021, 2017.

35. Zhang W, Wu Q, Wang C, Yang L, Liu P and Ma C: AKIP1 promotes angiogenesis and tumor growth by upregulating CXC-chemokines in cervical cancer cells. Mol Cell Biochem 448: 311-320, 2018.

36. Glynn PC, Henney E and Hall IP: The selective CXCR2 antagonist SB272844 blocks interleukin-8 and growth-related oncogene-alpha-mediated inhibition of spontaneous neutrophil apoptosis. Pulm Pharmacol Ther 15: 103-110, 2002.

37. Li A, Dubey S, Varney ML, Dave BJ and Singh RK: IL-8 directly enhanced endothelial cell survival, proliferation, and matrix metalloproteinases production and regulated angiogenesis. J Immunol 170: 3369-3376, 2003.

38. Eitel J, Heise T, Thiesen U and Dersch P: Cell invasion and IL-8 production pathways initiated by YadA of Yersinia pseudotuberculosis require common signalling molecules (FAK, c-Src, Ras) and distinct cell factors. Cell Microbiol 7: 63-77, 2005.

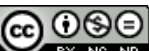

This work is licensed under a Creative Commons Attribution-NonCommercial-NoDerivatives 4.0 International (CC BY-NC-ND 4.0) License. 